\title{
A NOTE ON TRANSLITERATIONS
}

I have attempted to maintain a balance between readability and fidelity to Arabic, Hebrew, and Ottoman spelling. With that in mind, I have generally followed the transliteration guidelines set out in the International Journal of Middle East Studies. This will sometimes make for less than perfect reading, as in a sentence such as "imam and khatibi," but I have included a glossary at the end of the book for reference, should a term appear that is unfamiliar to the reader.

In some circumstances, such as "al-Qassamiyyun," I have adopted an Anglicized rendition (Qassamites) for purely stylistic reasons. This is also true of a few names with "accepted English spellings" that differ from the IJMES system, such as Yasser Arafat and Gamal Abd al-Nasser. 